\title{
OPTIMASI PENJADWALAN PRODUKSI MENGGUNAKAN PENDEKATAN ALGORITMA HARMONY SEARCH DI PT. ADI SATRIA ABADI (ASA)
}

\author{
Inaaratul Chusna Ichda Purwanto, Yohanes Anton Nugroho, Suseno \\ Program Studi Teknik Industri Universitas Teknologi Yogyakarta \\ chusnanaara@gmail.com, yohanesanton@uty.ac.id, suseno@uty.ac.id
}

\begin{abstract}
PT Adi Satria Abadi (ASA) is a company engaged in the processing of leather, especially sheep skin and goat skin, which is used for the manufacture of golf gloves. The problem faced by the company is the production process that exceeds the due date to other customers who order products at PT ASA. From the research, it is known that the cause is a company scheduling method that has not been organized so that the production sequence is concurrent. Selection of methods Harmony Search algorithms in scheduling are caused by delays. The Harmony Search algorithm can provide a better makespan value than the company method. The results of the company method obtain 0.9 months makespan average, the Harmony Search Algorithm method produces an average 0.8 months makespan. In addition, the use of the Harmony Search Algorithm method can reduce the average value of 0.1 months makespan. The results of the study in three months experienced time savings of 0.6 months, 0.6 months and 0.1 months respectively.
\end{abstract}

Keywords: scheduling, Maximum, Lateness, Mean, Flow

\begin{abstract}
Abstrak
PT Adi Satria Abadi (ASA) adalah perusahaan yang bergerak di bidang pengolahan kulit terutama kulit domba dan kulit kambing yang digunakan untuk bahan pembuatan sarung tangan golf. Masalah yang dihadapi perusahaan adalah proses produksi yang melebihi due date ke pemesan lain yang memesan produk di PT ASA. Dari penelitian, diketahui penyebabnya adalah metode penjadwalan perusahaan yang belum terorganisir sehingga sequence produksinya mengalami concurrent. Pemilihan metode Algoritma Harmony Search dalam penjadwalan disebabkan karena adanya keterlambatan.Algoritma Harmony Search dapat memberikan nilai rata-rata makespan yang lebih baik daripada metode perusahaan. Hasil metode perusahaan memperoleh rata-rata makespan 0,9 bulan, metode Algoritma Harmony Search menghasilkan rata-rata makespan 0,8 bulan. Selain itu, penggunaan metode Algoritma Harmony Search dapat mengurangi nilai rata-rata makespan 0,1 bulan. Hasil penelitian dalam tiga bulan mengalami penghematan waktu masing-masing sebesar 0,6 bulan, 0,6 bulan dan 0,1 bulan.
\end{abstract}

Kata kunci: penjadwalan, Maximum, Lateness, Mean, Flow

\section{PENDAHULUAN}

PT. Adi Satria Abadi (ASA) merupakan salah satu perusahaan internasional di wilayah Yogyakarta yang memproduksi sarung tangan golf berbahan baku kulit domba. Proses Produksi PT. ASA masih terbilang manual dan masih mengandalkan tenaga manusia, seperti menjahit dan pemotongan kulit. Proses produksi yang dilakukan pada perusahaan menggunakan system batch dengan model make toorder. Kapasitas produksinya mencapai 288.557 buah sarung tangan golf perbulan. Adapun factor yang menjadi pertimbangan dalam penjadwalan proses produksi di PT. ASA antara lain: jumlah bahan baku yang disediakan, jumlah stasiun kerja, jumah tenaga produksi, jumlah mesin produksi serta kebutuhan konsumen.

Permasalahan yang dihadapi perusahaan adalah proses produksi sarung tangan yang melebihi duedate ke pemesan lain yang memesan produk di PT. ASA, dengan kapasitas permintaan 3700 pcs. Makespan atau waktu produksi yang seharusnya selesai dalam satu bulan, terpaksa ditambah 1,5 bulan. Akibatnya, jadwal pengiriman produk mengalami lateness atau keterlambatan 0,5 bulan. Dalam hal ini, 
keterlambatan yang terjadi dipengaruhi oleh penjadwalan yang masih belum terorganisir, sehingga sequence produksinya mengalami concurrent pada stasiun kerja tertentu. Terjadinya concurrent mengindikasikan penjadwalan pada sistem produksi diperusahaan perlu dilakukan pembenahan.

Implementasi algoritma Harmony Search untuk penjadwalan produksi digunakan oleh Gunawan (2017). Penggunaan metode Algoritma Harmony search pada penelitian tersebut terbukti mampu mengurangi atau memaksimalkan permasalahan dalam penjadwalan proses produksi sarung tangan golf. Selain itu, metodeAlgoritma Harmony search diharapkan dapat membantu proses penjadwalan secara sequence digunakan oleh Aulia (2012). Berdasarkan latarbelakang masalah, maka peneliti berusaha merancang model penjadwalan menggunakan metode Algoritma harmony search dan mengangkatnya menjadi sebuah penelitian bidang industri manufaktur.

\section{TINJAUAN PUSTAKA}

Algoritma Harmony search diusulkan oleh Geem pada tahun 2001. Harmony search menirukan evolusi yang terjadi pada proses pertunjukan musik. Teknik ini menggunakan proses pencarian seperti pada improvisasi music yang berusaha mendapatkan keadaan terbaik berdasarkan perkiraan estetika. Dengan analogi tersebut, harmony search melakukan proses optimasi untuk mendapatkan keadaan terbaik dengan cara mengevaluasi fungsi objektif. Mirip perkiraan estetika yang ditentukan menggunakan himpunan pola-pola titik nada (pitches) yang dikeluarkan oleh alat-alat musik. Perbaikan nilai fungsi objektif pada harmony search menerapkan improvisasi yang terus ditingkatkan dari iterasi keiterasi, sama seperti pada perbaikan kualitas suara estetika yang diperbaiki dengan latihan demi latihan. Berdasarkan konsep algoritma diatas, berikut adalah langkah-langkah dari algoritma harmony search (Suyanto, 2010).

1. Inisilisasi Parameter

Pada tahap pertama, permasalahan optimasi ditentukan, sebagai berikut:
Minimasi $=f(x)$

dengan batasan $x_{i} \in X_{i} ; i=1,2, N$

Keterangan:

$f(x)=$ Fungsi objektif

$x i=$ Variabel keputusan

$X i=$ Himpunan variabel keputusan ke-i

$\mathrm{N}=$ Jumlah variabel keputusan

Pada langkah pertama semua parameter harus ditentukan kemudian parameterparameter harmony search yang lain juga harus ditentukan.

a. Harmony Memory Size (HMS) adalah jumlah vektor solusiy ang bisa disimpan dalam harmony memory.

b. Harmony Memory Considering Rate (HMCR) adalah probabilitas dari harmony memory untuk digunakan kembali sebagai hasil dari vektor solusi. Nilainya $0 \leq \mathrm{HMCR} \leq 1$, pada umumnya digunakan berkisar antara 0,7 sampai 0,95 karena jika rate terlalu rendah, maka hanya sedikit harmoni bagus yang terpilih dan juga dapat menyebabkan proses konvergensi (keadaan menuju satu titik) terlalu lambat. Jika rate terlalu besar, maka akan menyebabkan vektor solusi pada harmony memory banyak terpakai dan tidak sempat mengeksplorasi yang lain, di mana pada akhirnya sulit mencapai solusi yang baik (Setiawan, 2010).

c. Pitch Adjusting Rate (PAR) adalah parameter yang mempunyai peran signifikan dalam menentukan jumlah nilai yang harus diubah, disesuaikan atau ditukar dengan nilai yang lain. Nilainya adalah $0 \leq \mathrm{PAR} \leq 1$, umumnya digunakan berkisar antara 0,1 sampai 0,5 (Setiawan, 2010).

d. Kriteria berhenti merupakan banyaknya iterasi untuk melakukan improvisasi.

2. Inisialisasi harmony memory

Pada tahap ini dibangkitkan matriks harmony memory (HM) yang didapatkan 
dengan membangkitkan variabel keputusan $x_{i}$ secara random sehingga membentuk vektor solusi $x_{i}$, kemudian hitung nilai fungsi objektif $f(x)$ masingmasing vektor solusi. Berikut merupakan matriks harmony memory:

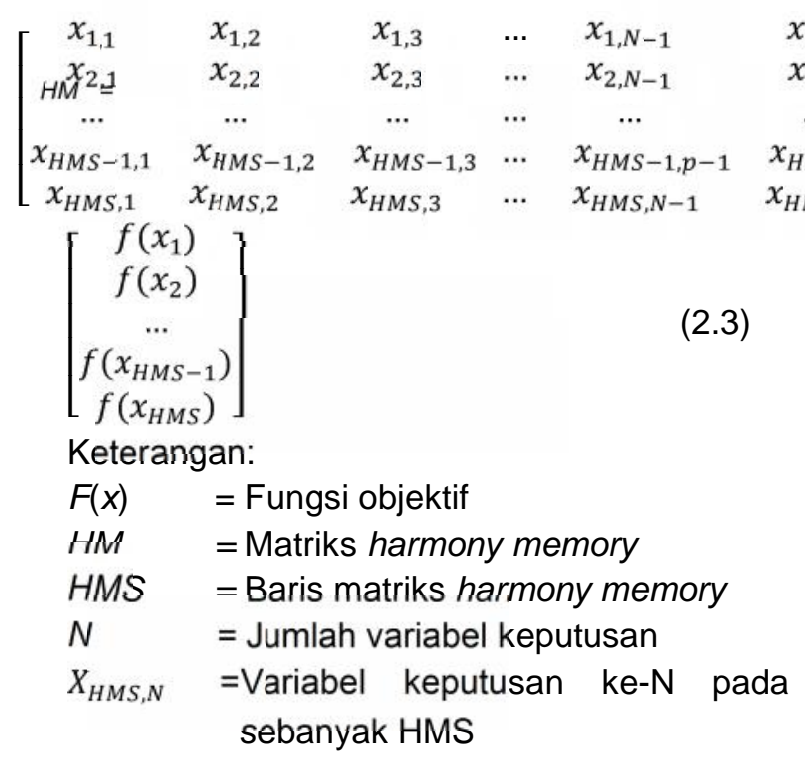

3. Improvisasi Harmony Baru

Dalam memperbaiki harmoni baru, $\left(x^{\prime}=x_{1}^{\prime}, x_{2}^{\prime}, \ldots, x_{N}^{\prime}\right)$ menggunakan dua aturan, yang diantaranya adalah:

a. HMCR (Harmony Memory Considering Rate)

Pada tahap ini nilai variabel keputusan $x^{\prime}$ dipilih secara acak dari variabelvariabel mana saja yang tersimpan dalamHM (Harmony memory) $\left(x_{i}^{1}, x_{i}^{2}, \ldots, x_{i}^{H M S}\right)$ dengan probabilitas $x^{\prime}$. Pembangkitan variabel keputusan yang tidak berada pada HM, maka akan dipilih secara acak dari himpunan variabel $x^{\prime}$ dengan probabilitas 1-HMCR. Pembangkitan variabel keputusan baru pada tahap ini menggunakan persamaan sebagai berikut:

$$
\begin{aligned}
& \quad x_{i}^{\prime} \\
& =\left\{x_{i}^{\prime}\left(\left\{\in x_{i}^{1}, x_{i}^{2}, \ldots, x_{i}^{H M S}\right\}\right) H M C R\right. \\
& x_{i}^{\prime} \in X_{i} H M C P_{i}-1
\end{aligned}
$$

b. PAR (Pitch Adjusting Rate)

Pada tahap ini merupakan tahap penyesuaian varibel keputusan baru $x_{i}$ yang dihasilkan pada tahap HMCR (Harmony memory consideration rate). Variabel keputusan tersebut akan disesuaikan dengan varibelvariabel yang berdekatan dengan probabilitas $H M C R \times P A R$. Variabel keputusan $x_{i}$ yang dihasilkan oleh harmony memory consideration rate dipertahankan dengan probabilitas HMCR $(1 \quad P A R)$. Penyesuaian variabel pada tahap ini ada dua formulasi yaitu variabel diskrit menggunakan aturan sebagai berikut:

$x_{i}^{\prime}=\left\{x_{i}^{\prime}(k+m) H M C R \times P A R\right.$
$x_{i}^{\prime} H M C R \times(1-P A R)(2.5)$

Keterangan:

$K=$ Indekspada elemen $X_{i}$ $x_{i}^{\prime}=$ Variabel keputusan ke- $i$

$X_{i}=$ Variabel ke- $k$ pada elemen $X_{i}$

$M=$ Indeks tetangga ( +1 atau -1$)$

4. Memperbarui Harmony Memory

Apabila dari vektor menemukan solusi baru, $\left(x^{\prime}=x_{1}^{\prime}, x_{2}^{\prime}, \ldots, x_{N}^{\prime}\right)$ dan pada vektor tersebut memiliki solusi yang lebih baik dibandingkan dengan vektor solusi terburuk didalam HM (Harmony Memory), vektor solusi baru tersebut dimasukan kedalam HM dan vektor solusi terburuk dikeluarkan dari HM, dan apabila nilai vektor solusi tidak lebih baik maka tidak akan terjadi perubahan pada HM.

5. Cek Kriteria Berhenti

Apabila kriteria pemberhentian telah tercapai, mka proses pengerjaan dihentikan. Apabila kriteria pemberhentian belum, tercapai maka akan kembali pada langkah ketiga dan keempat. Kriteria pemberhentian dari algoritma Harmony Search adalah jumlah iterasi yang telah ditentukan. Berikut merupakan diagram alir tahapan proses pada algoritma Harmony Search.

\section{METODE PENELITIAN}

Penelitian ini dilakukan di PT. Adi Satria Abadi (ASA) Jl. Laksda Adisucipto Km. 11 Ds. Sidokerto RT 03 RW 01 Purwomartani, Kalasan, Sleman, Yogyakarta 55571. Tujuan utama dari penelitian ini yaitu mengoptimalkan penjadwalan produksi dengan pendekatan 
algoritma harmony search. Tentunya salah satu bagian utama adalah melakukan assessment dan memberikan rekomendasi dan tindakan mitigasi

Penelitian dilakukan dengan berbagai metode, mulai dari wawancara, analisis metode pemodelan, inisialisasi parameter, desain masalah, studi pustaka, pengumpulan data, pengolahan data, analisis dan pembahasan, kesimpulan dan saran.Tujuan dari metodologi penelitian adalah agar pelaksanaan penelitian mendapatkan hasil yang sesuai dengan tujuan penelitian.

\section{HASIL DAN PEMBAHASAN}

Hasil perbandingan keterlambatan maksimum dari perusahaan dan algoritma harmony search, dengan menerapkan algoritma harmony search dapat meminimalkan lateness. Hasil yang diperoleh dari perhitungan langkah sebelumnya, bahwa perbulan rata-rata lateness dari metode perusahaan 2,7 bulan, sedangkan nilai ratarata untuk metode penjadwalan dari algoritma harmony search adalah 2,1 bulan. Minimalisisr lateness berkurang menjadi $38 \%$ dari $50 \%$ keadaan sebelumnya. Sehingga terjadi penghematan sebesar $12 \%$ atau rata-rata 0,6 bulan. Berikut adalah hasil perbandingan maximum lateness.

Tabel 1. Hasil Perbandingan Keterlambatan Maksimum

\begin{tabular}{|l|l|l|l|}
\hline \multicolumn{1}{|c|}{ Bulan } & \multicolumn{1}{|c|}{$\begin{array}{c}\text { Perusa- } \\
\text { haan }\end{array}$} & $\begin{array}{c}\text { Algoritma } \\
\text { Harmony } \\
\text { Search }\end{array}$ & $\begin{array}{c}\text { Penghem } \\
\text { atan }\end{array}$ \\
\hline Juli & 2.9 & 1.5 & 1.4 \\
\hline Agustus & 2.3 & 2 & 0.3 \\
\hline September & 3 & 2.8 & 0.2 \\
\hline Rata-rata & 2.7 & 2.1 & 0.6 \\
\hline Persentase & $50 \%$ & $38 \%$ & $12 \%$ \\
\hline
\end{tabular}

Analisis histogram menggambarkan hasil perbandingan nilai lateness dari perusahaan dan algoritma harmony search. Hasil pada histogram menunjukkan bahwa nilai maximum lateness perusahaan yang mempunyai titik tertinggi dan paling mendominasi selama tiga bulan. Penyebab terjadinya lateness yaitu proses produksi yang mengalami concurrent pada stasiun kerja tertentu.

Hasil dari metode algoritma harmony search meyakinkan bahwa nilai keoptimalan sangat berperan penting dalam meminimalisir maximum lateness. Berikut adalah hasil visualisasi diagram histogramnya.

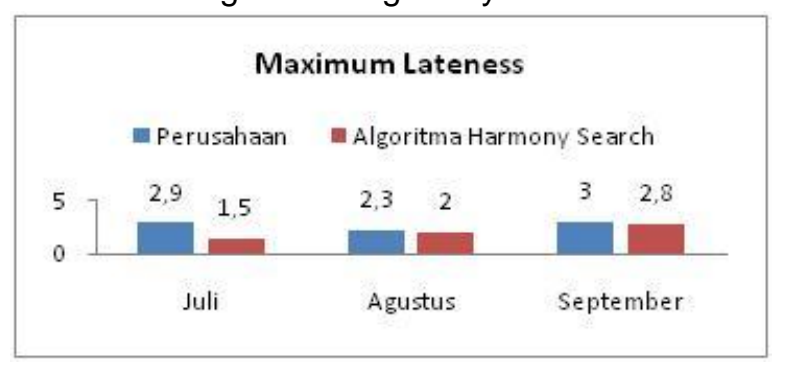

Gambar 1. Diagram Histogram Perbandingan Maximum Lateness

(Sumber: Olah Data, 2018)

Hasil yang diperoleh dari langkah perhitungan sebelumnya, bahwa dalam tiga bulan, waktu alir rata-rata (mean flow time) dari metode penjadwalan perusahaan adalah 2,7 bulan, sedangkan nilai rata-rata untuk metode penjadwalan dari algoritma harmony search adalah 2.1 bulan. Sehingga terjadi penghematan atau rata-rata $11 \%$ atau 0,6 bulan. Berikut adalah hasil perbandingan waktu alir rata-rata dari metode perusahaan dan metode algoritma harmony search.

Tabel 2. Hasil Perbandingan Waktu Alir Rata-Rata

\begin{tabular}{|l|l|l|l|}
\hline Bulan & Perusahaan & $\begin{array}{c}\text { Algoritma } \\
\text { Harmony } \\
\text { Search }\end{array}$ & $\begin{array}{c}\text { Penghe- } \\
\text { matan } \\
\text { MFT }\end{array}$ \\
\hline Juli & 2.9 & 1.55 & 1.35 \\
\hline Agustus & 2.3 & 2 & 0.3 \\
\hline September & 3 & 2.8 & 0.2 \\
\hline Rata-rata & 2.7 & 2.1 & 0.6 \\
\hline Persentase & $50 \%$ & $39 \%$ & $11 \%$ \\
\hline
\end{tabular}

Hasil pada histogram menunjukkan bahwa nilai waktu alir rata-rata perusahaan 2,7 bulan, mempunyai titik tertinggi dan paling mendominasi selama 3 bulan. Hasil dari metode algoritma harmony search meyakinkan bahwa, nilai keoptimalan sangat berperan penting dalam meminimalisir mean flow time, karena dapat meminimalisir 0,6 bulan. Berikut adalah hasil visualisasi diagram histogramnya: 


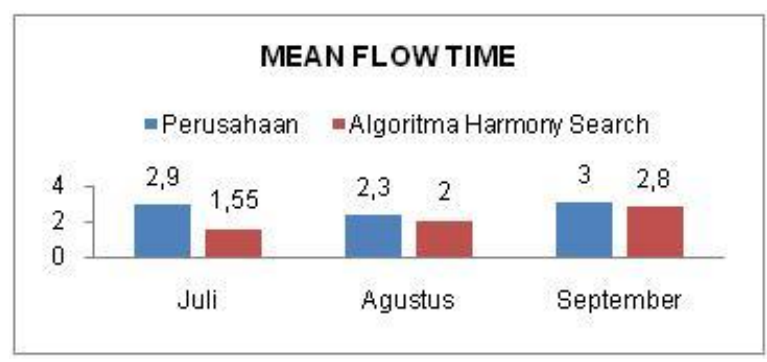

Gambar 2. Diagram Histogram Perbandingan Waktu Alir Rata-Rata

(Sumber: Olah Data, 2018)
Hasil analisis perhitungan pada metode perusahaan mempunyai makespan rata-rata 0,87 bulan, makespan rata-rata metode algoritma harmony search 0,81 bulan. Sehingga meyakinkan bahwa menggunakan metode algoritma harmony search lebih optimal dan berperan penting dalam meminimalisisr makespan. Berikut adalah hasil perbandingan makespan:

Tabel 3. Hasil Perbandingan Waktu Produksi (makespan)

\begin{tabular}{|l|l|c|c|c|c|}
\hline \multicolumn{1}{|c|}{ Bulan } & \multicolumn{1}{|c|}{ Metode } & $\begin{array}{c}\text { Kapasitas } \\
\text { Produksi }\end{array}$ & $\begin{array}{c}\text { Kapasitas } \\
\text { Perhari }\end{array}$ & $\begin{array}{c}\text { Makespan } \\
\text { (hari) }\end{array}$ & $\begin{array}{c}\text { Makespan } \\
\text { (bulan) }\end{array}$ \\
\hline Juli & Perusahaan & 491 & 400 & 10.5 & 0.35 \\
\hline & Algoritma Harmony Search & 391 & 400 & 10.0 & 0.33 \\
\hline Agustus & Perusahaan & 362 & 400 & 10.2 & 0.34 \\
\hline & Algoritma Harmony Search & 346 & 400 & 10.1 & 0.28 \\
\hline September & Perusahaan & 19393 & 400 & 57.7 & 1.92 \\
\hline & Algoritma Harmony Search & 19349 & 400 & 55.0 & 1.83 \\
\hline
\end{tabular}

(Sumber: Olah Data, 2018)

Analisis histogram menggambarkan hasil perbandingan makespan dari metode perusahaan dan algoritma harmony search.Hasil histogram menunjukkan bahwa nilai makespan dari metode algoritma harmony search lebih optimal 0,06 selama tiga bulan. Hasil dari metode algoritma harmony search meyakinkan bahwa nilai keoptimalan sangat berperan penting dalam meminimalisir nilai makespan. Berikut adalah hasil visualisasi diagram histogramnya.

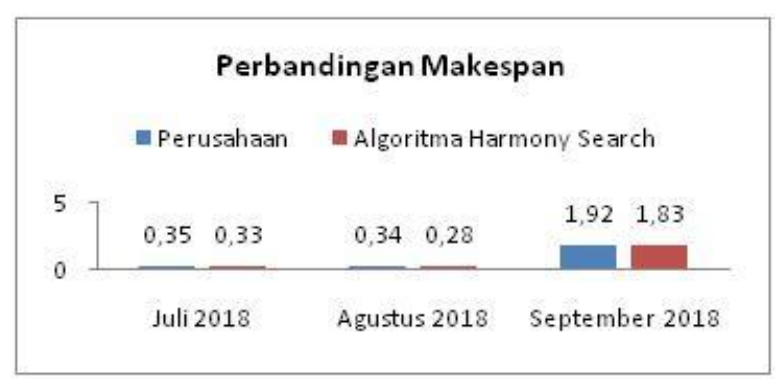

Gambar 3. Analisis grafik perbandingan (makespan)

(Sumber: Olah Data, 2018)

\section{SIMPULAN}

Hasil yang diperoleh dari perhitungan langkah sebelumnya, bahwa dalam tiga bulan rata-rata lateness dari metode perusahaan adalah 2,7 bulan, sedangkan nilai rata-rata lateness dari metode penjadwalan algoritma harmony search adalah 2,1 bulan. Minimalisir lateness menjadi $12 \%$, sehingga terjadi penghematan rata-rata 0,6 bulan.

Bahwa optimasi penjadwalan produksi terbukti dapat meminimalkan lateness. Hasil yang diperoleh mean flow time dari metode perusahaan adalah 2,7 bulan, sedangkan mean flow time dari metode penjadwalan algoritma harmony search adalah 2,1 bulan. Minimalisir mean flow time menjadi $11 \%$, sehingga terjadi penghematan rata-rata 0,6 bulan. Hasil yang diperoleh dari perhitungan dan analisis pada metode perusahaan mempunyai makespan rata-rata 0,9 bulan, sedangkan makespan algoritma harmony search mempunyai rata-rata 0,8 bulan, sehingga metode algoritma harmony search bisa meminimalisir 0,1 bulan. Meyakinkan bahwa menggunakan metode algoritma harmony search lebih optimal dan berperan penting dalam meminimalisir makespan.

\section{DAFTAR PUSTAKA}

Alfandianto Alex., Nugroho, Yohanes., Setiafindari, Widya. (2017). Penjadwalan Produksi Menggunakan Pendekatan Algoritma Genetika di PT Pertani (Persero).Jurnal Disprotek. ISSN 2088-6500.Vol 8 No. 2. 
Aulia, Indra., Nababan, Erna Budhiarti., Muchtar M.Anggia. (2012). Penerapan Harmony Search Algorithm dalam Permasalahan Penjadwalan Flow Shop.Jurnal Dunia Teknologi Informasi. Universitas Sumatera Utara.

Baker, K. R. 1974. Introduction to Sequencing and Scheduling.John Wiley \& Sons, Inc. Canada.

C. Worasucheep. (2011). A Harmony Search With Adaptive Pitch Adjustment For ContinuousOptimization. Journal Reviews Harmony Search, Vol. 4, No.

E. A. Zuliari. (2013). Harmony Search Algorithm (HSA) Untuk Optimal Power Flow (OPF). Jurnal Iptek Vol. 17, No. 1, Pp. 23-34.

I. Aulia, E. Nababan, And M. Muchtar. (2012). Penerapan Harmony Search Algorithm Dalam Permasalahan Penjadwalan Flow Shop.Dunia Teknologi InformasiJurnal. Vol. 1, No.1, Pp. 1-7.

M. Huang, S. Guo, X. Liang, And X. Jiao. (2014). Application Of Improved Harmony Search Algorithm In Test Case Selection. Journal of Software Vol. 9, No. 5, Pp. 1170-1177.

Setiawan, Achmad., dan Santosa, Budi. (2010). Penerapan Algoritma Harmony Search dalam Penyelesaian Resource Constrained Project Schedulling Problem.Institut Teknologi Sepuluh September. Surabaya.

Setiawan, Hendry., Kelana, Oesman Hendra., Gunawan, Dennys. (2017). Implementasi Algoritma Harmony Search Untuk Penjadwalan Produksi Plastik.Jurnal Kinentik Vol 2 No 2.Universitas Ma Chung.

Suyanto.(2010).Algoritma Harmony Search. Penerbit Andi.Yogyakarta.

Vollman, T. E., Whybark, dan Lee Berry W. (1998). Manufacturing Planning \& Control System, 4thEdition.McGraw-Hill Trade.

Z. Geem, K. Lee, And Y. Park. (2005). Application Of Harmony Search To Vehicle Routing. American Journal of Applied, Vol. 2, No. 12, Pp. 1552-1557. 